\title{
'You are not born being racist, are you?' Discussing racism with primary aged-children
}

\section{Naomi Priest, Jessica Walton, Fiona White, Emma Kowal, Brandi Fox \& Yin Paradies}

To cite this article: Naomi Priest, Jessica Walton, Fiona White, Emma Kowal, Brandi Fox \& Yin Paradies (2016) 'You are not born being racist, are you?' Discussing racism with primary agedchildren, Race Ethnicity and Education, 19:4, 808-834, DOI: 10.1080/13613324.2014.946496

To link to this article: http://dx.doi.org/10.1080/13613324.2014.946496

Published online: 04 Sep 2014.

Submit your article to this journal

Џ Article views: 776

Q View related articles $₫$

View Crossmark data $\nearrow$ 


\section{'You are not born being racist, are you?' Discussing racism with primary aged-children}

Naomi Priest ${ }^{\mathrm{a}, \mathrm{d} *}$, Jessica Walton ${ }^{\mathrm{d}}$, Fiona White ${ }^{\mathrm{b}}$, Emma Kowal ${ }^{\mathrm{d}}$, Brandi Fox ${ }^{\mathrm{c}}$ and Yin Paradies ${ }^{\mathrm{d}}$

${ }^{a}$ McCaughey VicHealth Centre for Community Wellbeing, University of Melbourne, Melbourne, Australia; ${ }^{b}$ School of Psychology, University of Sydney, Sydney, Australia; ${ }^{C}$ Centre for Research in Educational Futures and Innovation, Deakin University, Burwood, Australia; ${ }^{d}$ Centre for Citizenship and Globalisation, Deakin University, Burwood, Australia

Ethnic-racial socialisation is broadly described as processes by which both minority and majority children and young people learn about and negotiate racial, ethnic and cultural diversity. This article extends the existing ethnic-racial socialisation literature in three significant ways: (1) it explores ways children make sense of their experiences of racial and ethnic diversity and racism; (2) it considers ways children identify racism and make distinctions between racism and racialisation; and (3) it examines teacher and parent ethnic-racial socialisation messages about race, ethnicity and racism with children. This research is based on classroom observations, semi-structured interviews and focus groups with teachers, parents and students aged 8-12 years attending four Australian metropolitan primary schools. The findings reveal that both teachers and parents tended to discuss racism reactively rather than proactively. The extent to which racism was discussed in classroom settings depended on: teachers' personal and professional capability; awareness of racism and its perceived relevance based on student and community experiences; and whether they felt supported in the broader school and community context. For parents, key drivers for talking about racism were their children's experiences and racial issues reported in the media. For both parents and teachers, a key issue in these discussions was determining whether something constituted either racism or racialisation. Strategies on how ethnic-racial socialisation within the school system can be improved are discussed.

Keywords: racism; racialisation; ethnic-racial socialisation; children; teachers

\section{Introduction}

Well that is racism, I mean you are not born being racist are you? So that is something being passed on. (LPS Parent FG, 29/3/12)

*Corresponding author. Email: naomi.priest@deakin.edu.au 
As illustrated by the above statement made by a parent in this study, attitudes toward racial, ethnic and cultural diversity, including racist attitudes, are developed through complex ethnic-racial socialisation processes. Ethnic-racial socialisation refers to the processes by which children and young people learn about racial, ethnic and cultural diversity and includes verbal and non-verbal messages and behaviours about group membership and identity, social stratification and intergroup and intragroup relations. Research shows prejudice begins around three to six years of age when children's social cognitive ability is developing (Aboud et al. 2012). Children tend to show the greatest explicit levels of prejudice between four and seven years, followed by reduced prejudice after age seven (Raabe and Beelmann 2011). Thus it would appear that from an early age, children not only recognise race but are also socialised to form particular attitudes about themselves and people from different racial/ethnic backgrounds (Boutte, Lopez-Robertson, and Powers-Costello 2011). However, research on the actual messages that parents and teachers use to discuss race and racism with children, and children's readiness to understand these messages, is scarce. Additionally, there is very little research about how children and young people identify racism and conceptualise differences between racism and racialisation. The current study will aim to address this empirical gap by examining ways primary school children think about race and racism as well as how parents and teachers talk about these issues with them.

As the concepts of racism and racialisation form a focal part of this study, some clarification is needed. Racism refers to the ways in which avoidable and unfair inequalities are perpetuated based on racial, ethnic, cultural and religious characteristics at interpersonal, institutional and societal levels (Berman and Paradies 2010). In contrast, racialisation refers to the processes by which racial characteristics become meaningful in different social situations (Delgado and Stefancic 2001). Due to conceptual ambiguities and contextual specificities framing race-based speech and behaviours (Walton, Priest, and Paradies 2013a), racialisation is often conflated with racism, thus resulting in the belief that any mention of race is racist. This is often exacerbated by a widespread belief in colour-blindness, which claims to not notice or 'see' race or racial differences (Apfelbaum, Norton and Sommers 2012). These tensions can be understood in the context of postracialism or the belief in a society that has overcome race-based discrimination, rendering race an irrelevant factor when considering social inequity (Ono 2010). Related to colour-blindness and post-racialism are the concepts of 'racelessness' (Kempf 2012) and 'colourmute' (Pollock 2004). Based on research among Cuban teachers at a school in Havana, 'racelessness' can be understood as a 'strategic anti-racist stance' and a marker of a progressive society in which everyone is equal and race and racism are relics of the past (Kempf 2012, 263). 'Colourmute' refers to a process in which race-talk is actively silenced or removed in social interactions or written documents 
(Pollock 2004). Both colourmuteness and racelessness draw on notions of colour-blindness but for different purposes. Paradoxically, to be 'colourmute' is to recognise racial difference in order to actively remove mention of it, while 'racelessness' denies racial difference from the outset and aligns more closely with post-racial approaches in which race no longer matters.

Although research evidence demonstrates that children notice and attach meaning to racial differences from an early age, there is a paucity of evidence examining how children understand and identify racism. A recent review identified few qualitative studies that examine how young children learn about race and racism through their experiences of ethnic-racial socialisation with peers and adults (Una Qualitative Methods Learning Group 2010). Of existing studies, those using semi-structured, informal and openended interviews or group discussions, rather than structured interview or assessment tools, have predominantly focused on children's racial attitudes, as well as their own perceived racial and ethnic identity (Una Qualitative Methods Learning Group 2010). Other studies have examined children's perspectives and experiences of racism and interethnic/interracial friendships (Jaasma 2001; Pica-Smith 2009). However, there are few qualitative studies examining how children negotiate and conceptualise their understandings of race and racism or how they make sense of messages about race/ethnicity, racism, and racial/ethnic diversity. One qualitative study that did examine children's understanding of these issues found that seven- to 12-year-old Greek-Cypriot children (i.e., the majority group) did not think racism and nationalism were issues at their school whereas Turkish-speaking children (i.e., the minority group) identified many examples of everyday racism and nationalistic behaviours at the same school (Zembylas 2010, 318). Clearly, more qualitative research is needed before one can conclude that these differences in minority and majority children's perceptions of racism generalise to other cultural contexts.

Adults are critical influences on children's understandings of themselves and their worlds, through both implicit and explicit socialisation processes. In particular, parents play a pivotal role in young children's ethnic-racial socialisation, and are key influences on children's development of ethnic identity, intergroup attitudes and behaviours as well as understandings and responses to racial and ethnic diversity and racism (Priest et al. 2014). As children reach school age, teachers and the classroom also become significant sources of influence on children's ethnic-racial understandings (Paluck and Green 2009; Smith, Atkins, and Connell 2003). There are a number of situational and developmental factors that contribute to teachers' influence on children at this age. Brown and Bigler (2005) found that children's perceptions of racism in the school classroom were influenced by: (1) situational cues, such as a teacher of a particular race/ethnicity consistently 'favouring/ignoring' a student in class because of their race/ethnicity; (2) their social cognitive abilities, such as children's ability to make inferences 
about teachers' beliefs and biases, which develops around age seven to eight years of age; and (3) their sensitivity to racial/ethnic group information, where minority children are more likely than majority children to attribute a negative outcome for their group to racism, than an internal attribution of their group. Additionally, among fourth grade African American students, Smith et al. (2003) found their ethnic-racial attitudes were associated with those of their teachers, but unrelated to those of their parents. Given these differential findings, there is a strong rationale for understanding teachers' roles in children's understanding of racial and ethnic issues, as well as intersections between teacher and parent roles.

This current study aims to address these gaps in the ethnic-racial socialisation literature. The key aims of this article are to: (1) explore the ways in which children make sense of their experiences of racial and ethnic diversity and racism; (2) consider the ways in which children identify racism and make distinctions between racism and racialisation; and (3) examine teacher and parent ethnic-racial socialisation messages about race, ethnicity and racism with children. The article concludes by identifying promising approaches for encouraging a critical understanding of race and racism and promoting positive attitudes toward diversity in schools.

\section{The study}

A qualitative research approach was chosen as appropriate to the study aims, allowing for a critical, interpretive and open-ended exploration of how children conceptualise the racial and ethnic diversity they negotiate, and how these conceptualisations are influenced, and different from, those of their parents and teachers. These study aims are highly consistent with those of qualitative research; that is studying everyday life in naturalistic settings and attempting to understand how people make sense of their social worlds (Denzin and Lincoln 2011). Thus, a qualitative method was chosen because the aim of this study was to understand a phenomenon from the perspective of the research participants (Rice and Ezzy 1999).

More specifically, this study, and its methodology, was strongly guided by anti-racism approaches and critical race theory in understandings of race and racial privilege. Importantly, anti-racism and critical race theory both acknowledge the limitations of essentialist notions of race and anti-racism, but maintain the salience of a raced analytic viewpoint. These theories advocate that the role played by race as a social construct in structural inequalities be accounted for, rather than denied under the seductive myth of post-racialism (Howard and Flennaugh 2011) that also strategically ignores racism (Kempf 2013; Smith and Lalonde 2003).

The focus on children's constructions and negotiations of racial and ethnic diversity, was grounded in the sociology of childhood that argues children's views and perspectives should be taken seriously, with children 
engaged in research that 'recognises them as subjects rather than objects of research, who "speak" in their own right and report valid views and experiences' (Alderson 2001; Morrow 2001). As highlighted in the introduction above, few research studies have engaged directly with children and young people themselves regarding how they learn about, and identify racism, and how they conceptualise differences between race and racialisation. In addition, the existing literature whilst focusing on children's views and perspectives, still tends to engage with a fairly limited range of children's social backgrounds, with alternative children's voices such as those from non-white and/or ethnic minority communities often missing (Atree 2007; Clavering and McLaughlin 2010).

In this wider theoretical context of anti-racism, critical race theory and sociology of childhood, a case-study approach was used in this study with schools as the primary unit of analysis (Yin 2009). As case studies are not meant to be generalisable at a statistical level (Yin 2004, 2009), we selected particular schools that would provide an in-depth understanding of how ethnic-racial socialisation operates in different contexts. Four primary schools across metropolitan Melbourne, Australia, were selected to capture a diverse demographic in terms of racial-ethnic diversity and socio-economic status. These schools were identified in consultation with state education department multicultural policy staff, service providers running refugee and new arrival programs in schools, ethnic community peak body representatives, as well as with the funding body, a state government funded health promotion foundation. After consultation with these key stakeholders, school principals were contacted to discuss the study and invite them to participate. Interested school principals then approached their staff and parent communities regarding the study, and invited the researchers to discuss the study further at staff meetings and parent forums as appropriate within each local school context. As well as obtaining consent from each school principal, informed consent for participation in data collection was also obtained from individual teachers, parents (for themselves and for their children), as well as assent from students. Information sheets and consent forms were translated to languages other than English as appropriate for each school community. Ethics approval was received from University of Melbourne [HREC \#1,238,446] and the Department of Education and Early Childhood Research Department [2011_001164]. All participants provided informed consent. All names and identifying details of schools and individuals have been changed to ensure anonymity.

Two of the participating schools comprised mainly Anglo-Celtic students from mid- to high-socioeconomic backgrounds (Lynvale Primary School [LPS] and High Flats Primary School [HFPS]) and two schools had students from low- to mid-socioeconomic backgrounds. The other two schools included one school where the majority of students had first and second generation migrant and refugee backgrounds from East African countries 
such as Ethiopia, Somalia and Eritrea (Middleburn Primary School [MPS]), and the other school with a significant proportion of students from first and second generation migrant or refugee backgrounds from countries in South and Southeast Asia and the Middle East, with over 60 different countries of origin represented among the students' families (Clarewood Primary School [CPS]). Refer to Table 1 for a description of students who participated in the focus groups by gender, year level and ethnic minority/majority group status.

Due to the small sample size and the distinct cultural make-up of some of the schools, identifying information such as specific geographic location and individual teacher and student background including age, specific information about cultural background and length of time at the school have been omitted. Additionally, pseudonyms have been used to protect anonymity of participants and schools. All teachers and key school informants discussed their ethnic-racial background and all except one were white European Australians, which included mainly Anglo-Celtic as well as some Western European and Mediterranean backgrounds. Finally, all key informants were female and all but five teachers were female.

Data collection included focus groups, individual interviews and classroom observations. Focus groups were conducted separately with students, parents and teachers in each school between September 2011 and March 2012. Individual semi-structured interviews were conducted during the same

Table 1. Focus group participant demographics by school.

\begin{tabular}{|c|c|c|c|}
\hline & $\begin{array}{l}\text { Students } \\
(\mathrm{n}=67) \\
\text { Year level }\end{array}$ & Gender & $\begin{array}{l}\text { Minority/majority } \\
\text { ethnic group } \\
\text { status }\end{array}$ \\
\hline \multirow[t]{4}{*}{ Middleburn Primary School (MPS) } & Year 3/4 & $\begin{array}{l}2 \text { boys } \\
2 \text { girls }\end{array}$ & $\begin{array}{l}\text { All minority } \\
\text { All minority }\end{array}$ \\
\hline & Year 5 & $\begin{array}{l}4 \text { boys } \\
4 \text { girls }\end{array}$ & $\begin{array}{l}\text { All minority } \\
\text { All minority }\end{array}$ \\
\hline & Year 6 & 4 boys & 3 minority \\
\hline & & 2 girls & All minority \\
\hline \multirow[t]{5}{*}{ Clarewood Primary School (CPS) } & Year 3 & $\begin{array}{l}3 \text { boys } \\
4 \text { girls }\end{array}$ & $\begin{array}{l}\text { All minority } \\
2 \text { minority }\end{array}$ \\
\hline & Year 5 & 1 male & 1 minority \\
\hline & & 1 female & 1 majority \\
\hline & Year 6 & 2 boys & All minority \\
\hline & & 6 girls & All minority \\
\hline \multirow[t]{2}{*}{ High Flats Primary School (HFPS) } & Year 4 & 7 boys & All majority \\
\hline & & 7 girls & All majority \\
\hline \multirow[t]{2}{*}{ Lynvale Primary School (LPS) } & Year 5/6 & 10 boys & All majority \\
\hline & & 8 girls & All majority \\
\hline \multirow[t]{2}{*}{ Total: } & & 33 boys & 36 majority \\
\hline & & 34 girls & 31 minority \\
\hline
\end{tabular}


time period with key school informants $(\mathrm{n}=14)$ and four parents, including three who required an interpreter. Overall, participants included 67 students in Years 3-6 (8-12 years old), 21 parents, 27 teachers and 14 key school informants. Focus groups were semi-structured (Morse and Richards 2002; Willis et al. 2009) and guided by schedules that included questions about racial, ethnic and cultural diversity, identity and ethnic-racial socialisation messages, behaviours and beliefs. Students were also asked about ethnicracial socialisation sources, or to whom they would talk in order to learn about their own culture and other cultures, and views about things they felt were good and not so good about their cultural background. Specific questions for teachers and parents included awareness of students' cultural backgrounds and intercultural student friendships, and views about the importance of teaching or talking about cultural diversity. A set of four intercultural scenarios, exploring situations such as race-based discrimination on a tram, were also presented to teachers, parents and students to determine how students felt parents and teachers would respond and correspondingly, how parents and teachers felt they would respond to students in terms of key messages and behaviours. Focus group schedules were developed from an extensive review of ethnic-racial socialisation research in order to identify key themes for exploration (Priest et al. 2014). They were also informed by literature regarding best practice conduct of focus groups, particularly with children, that recommends the use of multiple methods such as scenarios as well as facilitated discussion around key questions of interest (Baker and Weller 2003; Darbyshire, MacDougall and Schiller 2005; MacDougall and Fudge 2001; Morgan et al. 2002; Punch 2002). Scenarios were also used to minimise groupthink and reduce social desirability bias in order to stimulate open discussion particularly among parents and teachers (MacDougall and Baum 1997). Such methods are particularly important when discussing issues such as racism that are bound by strong social conventions regarding political correctness and appropriate opinions (Supphellen, Kvitastein, and Johanson 1997).

Focus groups with students were held at each school during lesson time and outside classrooms such as in the library or art room. Focus groups with parents and teachers were held both during and after school hours as negotiated with each school. Two researchers conducted each focus group; all focus group facilitators were women, and they identified as having Anglo-Australian, Korean American, Jewish and Native American racial, ethnic and cultural backgrounds. As recommended in the literature (Morgan et al. 2002), researchers provided food and drink for all participants and shared simple personal information about their own racial/ethnic backgrounds to build rapport and reduce power imbalances related both to racial/ethnic background and to adult/child dynamics. As focus groups were conducted following the classroom observations, students were already familiar with the researchers as they had been present in the classrooms for 
several weeks. Translators were provided to parents when needed, with one of the researchers being fluent in Arabic. Power dynamics between participants, and between researchers and participants, were carefully negotiated by the researchers drawing on their considerable experience in focus group facilitation with children and adults from minority backgrounds including migrants and refugees. Teachers and parents were not present in the student focus groups, and it was carefully explained to students that the researchers would not be telling adults who had said what, and that no individuals would be identified in the research findings.

Key informant interviews were also guided by semi-structured schedules (Cohen, Manion and Morrison 2007; Morse and Richards 2002), although scenarios were not used in these discussions. These key informant interviews were conducted separately with school principals and leadership staff rather than including them in focus groups with classroom teachers in recognition of potential power issues between senior school leadership staff and the teachers reporting to them.

Classroom observations were conducted by at least two researchers in each school for a total of 45 hours across all four schools during class time between November 2011 and March 2012. Each school was visited five to nine times over a one-month period. A guide was used to document verbal and non-verbal interactions between teachers and students and amongst students. School staff informant interview schedules were used to understand the broader school and community context regarding awareness of cultural diversity, intergroup relations and school approaches to discussing cultural diversity such as curriculum, programs and community visits.

Before, during, and after data collection, as well as throughout analysis, the researchers met regularly to debrief and reflect on data collection process and emerging analysis in order to promote reflexivity and rigour. This was particularly pertinent given members of the research team included members of both minority and majority racial/ethnic backgrounds.

All data were thematically coded drawing on pre-determined categories as well as inductive emergent codes. Comparative analysis was used to determine patterns within and across schools, and between parents, teachers and students. Researchers from both minority and majority backgrounds coded and analysed the data, thus being inclusive of multiple interpretations of the data from their different ethnic/racial subject-positions and experiences. Informed by critical race theory, we analysed the data using a raced analytic viewpoint to understand ethnic-racial socialisation from the perspective of children from majority and minority racial-ethnic backgrounds, as well as their parents and teachers. As Hylton (2012) highlights, such a focus on race is not intended to be essentialist, nor is it intended to deny the complexities of the intersections between race and other socially constructed categories, such as gender and class. Rather, as per critical race theory, our focus on race and racism in this study acts as a starting point to challenge 
multiple forms of oppression. As an exploratory study, we chose to focus our analysis on race and racism within the context of ethnic-racial socialisation, with a view to exploring intersections with gender and class in future work.

The following findings and discussion sections examine children's experiences and understanding of racism alongside teachers' and parents' views about racial-ethnic diversity and racism with children. Other findings relating to ethnic-racial socialisation messages about egalitarianism and colour-blindness are discussed elsewhere (see Walton et al. 2014).

\section{Findings}

\section{Children's experiences of racism}

Findings revealed that students across all four schools were well aware of racism, although there was heightened awareness among students from visible minority backgrounds who had experienced racism themselves. These students described experiences of racism perpetrated by their classmates from both majority groups and other minority groups, as well as by people in the wider community. Additionally, students described other examples of racism they had heard about or witnessed as bystanders.

Students from East African backgrounds at MPS discussed racism experiences considerably more often than students from other minority backgrounds at this or other schools. The Grade 3/4 teacher, Andrew, asked students to name racist things people have said to them. Students listed a number of blatantly racist statements as well as a few racialised statements about skin colour that may or may not have been racist.

Student 1: $\quad$ The f-word.

Student 2: A [white] boy in the park said to me, 'Your skin is navy blue'.

Student 3: $\quad$ You're so dark.

Student 4: In the lift [of the housing commission flats he lives in] a man said to me and my friend, 'You f-ing black people go back to Africa' and he said the f-word.

Student 5: $\quad$ You're not meant to be here.

Student 6: The [white] lady next door said, 'You black people, go back to where you came from, go back to Africa, you don't belong here' and we said, 'Why don't you? You don't even own this, the Aboriginal people do' [...]

Student 7: $\quad$ The n-word [...]

Student 8: $\quad$ I don't like your skin colour. (MPS Grade 3\&4 Classroom Observations, 15/11/11)

Although the experiences students described were mainly between themselves and white people, another student who identified as both Eritrean and Saudi Arabian explained that people at her Arabic language school had 
teased her about her darker skin colour relative to her classmates with lighter skin colour (MPS Grade 5 Student FG, 13/12/11). The interviewer prompted by asking, 'In what ways?' At this point, another student jumped in and said, 'Because you are black'. To this the student replied somewhat relieved, 'I thought you were going to say white', implying that because of her multiracial appearance, she might be seen as 'white' or 'different' at MPS where the majority of students have darker skin colour. She then went on to say, 'They kept on teasing me and calling me black. When I was little, I was dark-skinned'. The same student who commented earlier then added quietly, 'Because you are not black', recognising that the student has lighter skin colour than most of the students at MPS.

The student's experience of racism from other minority students for being categorised as 'black' is reminiscent of what Washington (1990) calls 'brown racism'. This term refers to racism by other minority group members who do not necessarily fit within a white-black dichotomy toward people of African descent. He explains that 'brown racism' is partly about attempting to associate oneself with an idealised position connected to having fairer skin colour combined with the power of white privilege. The student's darker skin colour was the focus of her classmates' derision in her Arabic language school, whereas in other contexts, such as at MPS where there is a majority of students with darker skin from African backgrounds, her skin colour was perceived to be more 'white' or 'not black'. Furthermore, rather than seeing race as an immutable category, students began to think about how racism is based on socially constructed meanings attached to skin colour, where they could be seen as 'black', 'white' or somewhere in-between depending on the social and cultural context. Beyond the physical appearance of skin colour, social meanings attached to what it means to be 'black' or what it means to be 'white' are also context-dependent. This echoes Stuart Hall's description of how he 'became black' when he migrated to England, noting the ways in which 'blackness as a political identity ... is always complexly composed, always historically constructed' (2000, 152).

While personal experiences of racism tended to be reported by students from East African backgrounds, this was not so for students of East Asian backgrounds. This was surprising given racist attitudes towards people from East Asian backgrounds were evident within focus groups and classroom discussions. One scenario asked students to imagine they learnt about aspects of Chinese culture at school and then decided they themselves want to be Chinese because they find it so interesting. The scenario was used to explore whether students, especially Anglo-Celtic students, might discuss their cultural identity (or apparent lack thereof) as well as explore issues related to stereotypes and exoticism. However, in addition to students' comments that their parents or teachers would encourage them to learn more about Chinese cultures rather than trying to 'be Chinese' (i.e., assume 
another ethnicity), the scenario also elicited racist comments. At HFPS, one student explained why he would not want to be Chinese:

Interviewer: What else would they say do you think if you said, 'I want to be Chinese. I don't want to be from my background'?

Student: If I said I want to be Chinese, personally I wouldn't want to be Chinese.

Interviewer: How come?

Student: $\quad$ Because I think it's just something with Chinese, I think that they all look the same and I don't want to look the same as somebody else, it would be a bit freaky and being like Matt [a classmate]. (HFPS Grade 4 Student FG\#1, 17/11/11)

At CPS, students drew on common stereotypes of Chinese people:

Student 1: $\quad$ And some of them are rude.

Interviewer: Who are rude?

Student 1: $\quad$ Some of the Chinese people.

Interviewer: $\quad$ Some of the Chinese people are rude.

Student 1: Yes, they're rude and they have long moustaches and they look very ...

Student 2: $\quad$ Old?

Student 1: $\quad$ No, some of them look very, really ...

Student 3: $\quad$ Weird.

Student 1: $\quad$ No, not weird.

Student 4: $\quad$ Scary. (CPS Grade 3\&5 Student FG, 24/11/11)

These stereotypes were not identified as racist by other students. An exception involved two Grade 5/6 students. While mimicking epicanthic folds to demonstrate what one student observed another student doing, he said, 'She's being racist. She's pulling her eyes like this' to which the student replied, 'Chinese have really small eyes' (MPS Grade 5\&6 Classroom Observations, 22/11/11). Only moments earlier, the students had debated whether calling someone 'black' if the person doing so was also 'black' was racist. Similarly, as an example of the ambiguity between racialised and racist behaviour, the student may or may not have thought that pulling her eyes to imitate the epicanthic fold, commonly associated with people from East Asian countries, was racist when she stated that Chinese people have small eyes as it may have been more about demonstrating eye shape.

When students were asked to think about what racism is, most students explained that it is about treating people differently in a negative way because of their skin colour. However, there was some confusion around whether simply talking about skin colour was racist. At MPS, the teacher, Andrew asked the students what the difference was between being rude and being racist. Students replied, 'Rude is saying mean things. Racism is about country and skin colour' and 'How we look'. During this discussion, students also began to think more about how they might identify something 
as racist. At the start of the lesson, a student commented, 'Some people have different coloured skin' to which other students responded, 'That's racist'. Andrew pointed out, 'I don't think that's racist because that's a fact', referring to a common misconception that any mention of race or skin colour (racialisation) is automatically 'racist' (Giroux 2006). When students such as those at MPS were encouraged to explore their understanding of racism, they also began to articulate subtle differences between racialisation and racism. The ways in which children understand and identify racism is discussed in the next section.

\section{Children's approaches and responses to discussing race and racism}

Racism was discussed as a core part of classroom lessons at MPS. Consequently, the majority of findings on race and racism are from this school. However, whether or not racism was explicitly discussed in classrooms, students from all schools discussed their understanding of racism to some extent in the focus groups as illustrated by the following quotes:

Some people are judged by the cover of them and are not judged by the heart.

(LPS Grade 5\&6 Student FG\#1, 19/03/12)

$\begin{array}{ll}\text { Student: } & \text { Shouldn't be racist. } \\ \text { Interviewer: } & \text { What do you mean by that? } \\ \text { Student: } & \text { Like when someone has a dark skin you call a name. }\end{array}$

(CPS Grade 3\&5 Student FG, 24/11/11)

HFPS, the majority white, high socio-economic status school, was the only site where students did not discuss racism in any depth either in focus groups or classroom discussions. Students there participated in a weeklong curriculum unit on Aboriginal culture lead by an Aboriginal elder and educator. Although the curriculum unit was centred on understanding Aboriginal cultures, reproductions of traditional representations and interactions between Aboriginal people and Europeans, racism was not discussed. During a lesson, one of the students repeatedly tried to talk about skin colour; however, teachers and other students did not engage with this topic. The only occasion when inequality was mentioned was in response to a scenario that asked if it was okay to talk about different cultures. One student decided it was acceptable to talk about people from other cultures as long as it is done nicely equating this with 'treating them fairly' (HFPS Grade 4 Student FG\#2, 17/11/11).

Many of the students at MPS seemed to have experienced racism in their community because their darker skin marked them as more visibly 'different'. They were often quick to identify something as racist if there was mention of someone's skin colour. However, when pressed by their 
teacher to think further about why some behaviours were racist and others were not, they began to question their initial thoughts about racism. During focus groups, students were presented with hypothetical scenarios highlighting racism. This prompted them to consider other factors affecting how people in each scenario might react. For example, one scenario asked students how their parents and teachers would respond if they were on a full tram and yet nobody would sit next to a man with dark skin. A few responses directly attributed racism as a possible explanation:

If I asked [my mother] why they are doing that, she would say, 'Because they are really bad people and they're not, they don't care about, they're racist'.

Or, like $[\ldots]$ they think their skin colour [is] disgusting and they don't like their skin colour. (MPS Grade 5 Student FG, 13/12/11)

My parents would probably say that it is racism and if you want to make him feel better we could go sit next to him. (LPS Grade 5\&6 Student FG\#2, 19/03/12)

These students defined racism as a negative valuation of skin colour. During a classroom discussion, Grade 5/6 students at MPS also described racism as 'insulting someone's colour, religion or culture'. However, others disputed whether racism includes religion:

Student 1: $\quad$ It's about race not religion because it has the word race in it.

Student 2: You can't tease religion because you might have someone with light skin that is a Muslim and maybe dark skin is a Christian.

Student 3: $\quad$ It's usually about skin colour, race.

Student 4: $\quad$ But people tease you about what you believe in [...]

Student 5: Ridiculing someone's culture or putting religion down. Racism is where people don't treat other races equally. (MPS Grade 5\&6 Classroom Observations, 15/11/11).

These students tried to understand whether any kind of demeaning comment about someone's culture, skin colour or religion, qualifies as racism, thus tapping into the way religion is often conflated with ethnicity and culture (Hartmann et al. 2011). Moreover, whilst in Australia culture is not synonymous with race or ethnicity, culture is commonly used as a proxy for, and conflated with race, ethnicity and/or religion (Moran 2011). In contrast, others have argued that conflating race, ethnicity and/or religion with culture serves to mask the social significance of race (Castagno 2008), and thwarts efforts to effectively identify and address racism (Apfelbaum et al. 2010).

As students tried to understand the situation in more detail, they began to interpret the actions of people on the tram by considering other factors. 
For instance, when clarifying who was potentially being racist to whom, a student asked, 'Was it the Indian guy [referring to the man with darker skin] and then the Australian white people?' The interviewer said, 'It could be a mix of cultural people on the train. Who do you think it would be most likely to happen with?' The student then responded with:

White people [...] Most of the time I have not seen Australian people, white people being racially abused. It's mainly people, immigrants from other countries like Vietnam or Africa, and they are being racist and they will call Italian people a wog. ${ }^{1}$ (MPS Grade 6 Student FG, 19/12/11)

Based on situations the student had witnessed, he understood that it is usually people from minority groups who are targets of interpersonal racism. As the discussion progressed, another student asked if people could be racist if both the perpetrator and the target were of the same background:

What if there's an Indian person with the same background, the same colour, the same everything and there was another Indian man or something and they were still not sitting next to him, that wouldn't exactly be racist because if they're from the same tribe and area, so because who would want to be racist against their culture? (MPS Grade 6 Student FG, 19/12/11)

In response to this, a Somalian Australian student suggested that like in Somalia, they might be from different warring tribes and therefore while they may have similar backgrounds they might not get along. Students also discussed other possible explanations including irrationality, choosing to stand and inappropriate behaviour.

If it was my aunty, she would say, 'Those people are so stupid, there's a free seat on the tram, come on this tram is crowded.' (MPS Grade 6 Student FG, $19 / 12 / 11)$

Most of the people would be on them [holding tram straps] like next to the chair so the person closest to them they would probably be the one who's being most racist. Because they're so close to an empty chair but they don't want to sit there. But sometimes some people don't feel comfortable around other people, not just Indian people. Like, if someone saw a random person there someone might not sit next to them because you don't want to feel too like claustrophobic. (MPS Grade 6 Student FG, 19/12/11)

My parents would probably say they should sit next to [...] but some people think people who are different colours and from different countries are not welcome in Australia. Or he might have done something gross, like pick his nose or something and people did not want to sit next to him. (LPS Grade $5 \& 6$ Student FG\#2, 19/03/12)

While students were primarily asked to think about how their parents and teachers might respond, they also gave a range of possible explanations 
regarding what they thought was happening and why. It became apparent during the focus group and classroom discussions that students not only understood and experienced racism, some students also engaged in sophisticated discussions about it, such as considering whether racism can be based on religious differences and the inherently relational and specific nature of racism (Berman and Paradies 2010) as being more than simply an aversion to sitting next to 'random people'.

\section{Teacher and parent approaches and responses to discussing race and racism}

\section{Teacher approaches}

Teachers at all four schools differed in the extent to which they explicitly engaged in discussions about racial, ethnic and cultural diversity with students as well as in whether they took a critical multicultural approach by talking about racism (Sleeter and Grant 2009). While all teachers highlighted the importance of students learning about cultural diversity, school demographics had an impact on how relevant teachers felt it was to discuss racism. Furthermore, teacher confidence impacted the extent to which students were encouraged to engage in discussion about racism.

Only teachers at MPS discussed racism on multiple occasions as a central focus of classroom lessons. This focus may have corresponded with their awareness of racist experiences among various minority groups in their community. Based on classroom observations, MPS teachers were comparatively more skilled and confident in these discussions as opposed to diverting or silencing them, which happened more often at the other schools. This may be related to the inner-urban location of the school and the high number of students from culturally diverse backgrounds, which might attract teachers with a particular interest in critical multicultural pedagogy. Conversely, teachers at CPS, which is an outer-suburban school, did not discuss racism even though the student population included a high proportion of students from minority backgrounds who were likely to experience racism in their community. Instead, the focus was on learning about other cultures, including stereotypical depictions of Australian 'ocker' ${ }^{2}$ culture and archaic examples of Australian slang. Moreover, in the process of teaching about cultural diversity, there were multiple occasions when stereotypical representations of different cultures were reinforced. Furthermore, with the exception of MPS, teachers at the other three schools focused primarily on culture rather than race or ethnicity, emphasising sameness while glossing over how certain differences are made to matter in society. This is a typical approach, especially given most teachers are from Anglo-Celtic backgrounds, operate from an undisrupted position of white privilege, and may not know how to think about or discuss racism (Moon et al. 2009; Pollock 2004). 
At HFPS, even when European colonisation was discussed, teachers did not bring up racism or skin colour. After reading a story in which a young Aboriginal boy visited a cattle station, a Grade 4 teacher, Adam, asked the students why they the station owners might have stared at the boy (HFPS Grade 4 Classroom Observations, 19/10/11). A student responded, 'Because he has a different skin colour.' This same student had also raised skin colour the previous day when discussing a misunderstanding between a white policeman and an Aboriginal person. Rather than responding to the student, Adam effectively silenced him by diverting the conversation with, 'How would you meet your family and friends?' Distinguishing between teacher silence (e.g. not intervening when students are making racist comments) and active silencing (e.g. silencing students when they make comments about race rather than engage in discussion), Castagno argues that both approaches serve to 'support and possibly perpetuate racist beliefs and actions' (2008, 322). By remaining silent on how race is made meaningful, white privilege is maintained and the normality of race-based inequalities is reinforced rather than disrupted.

The HFPS approach to lessons was likely influenced by the school's emphasis on acceptance regardless of differences, and supported by teacher beliefs that their students do not notice difference. Related to colourblindness which is 'the belief that racial group membership and race-based differences should not be taken into account' (Apfelbaum et al. 2012, 205), teachers claimed that while students recognised difference, difference did not play a part in who they chose to interact with at school. When asked if they felt it was important for students to be friends with people from different cultural backgrounds, a few teachers commented that difference was not something they stressed as 'important' or drew attention to as they felt students just got along 'quite naturally' as a part of just 'what we do'. This claim runs counter to observations and student discussions identified earlier in which students with Chinese backgrounds were discriminated against.

I don't know if the kids actually see a whole lot of difference in each other, yeah sure they might be aware that [a student is] Indian or whatever but there's no kind of, 'You're Indian, you need to stay with that particular group' or whatever but they just seem to just intermingle quite naturally. There's no thought about the fact that they're from another culture. (HFPS Teacher FG, 24/11/11)

Instead of considering the significance of race and ethnicity in student friendship groups, the teachers took a position of 'racelessness', which moves beyond a reluctance to talk about race toward an insistent denial that race matters (Kempf 2012). For instance, in response to the tram scenario discussed above, some teachers actively discounted racism as a possible explanation, stating: 'It's just ignorance or not knowing sometimes' and 'See you don't know, you assume that it's a racial thing. You don't know what the reason is' (HFPS Teacher FG, 24/11/11). 
Teachers at LPS discussed the 'Stolen Generations' child removal policy $^{3}$ and the White Australia Policy during observed classes. However, surprisingly racism was not explored in any depth, and was only partially mentioned even when students made explicit comments about skin colour or racism. During a lesson, teachers Blake and Lisa used a video of an Aboriginal girl's story to discuss the 'Stolen Generations' (LPS Grade 5\&6 Classroom Observations, 15/02/12). They began with a list of keywords from the video. Lisa referred to one of the words asking, "Mistreatment, what does that mean?' A student replied, 'Not treated right. "Mis" means "not". Other students explained that mistreatment just means "wrong treatment' and could be 'not only people but trees' and 'not treating a toy properly'. Another student asked, 'Would it be people pushing you around and bullying you?' to which Lisa responded, 'Bullying is a form of mistreatment'. A fifth student identified slavery as a form of mistreatment and mentioned the word 'race' by explaining, 'I've heard of several races being kidnapped. It's when you keep something, usually a person and you keep it for your own good'. Further along in the discussion, a student connected the treatment of Indigenous people with slavery saying, 'A long time ago, people used to treat Indigenous people as slaves, treat them like dogs. [They] didn't think the Indigenous people were equal to them'. Blake prompted with, 'Which Indigenous people?' and the student explained that he meant all Indigenous people. The other issues the student raised about inequality and slavery were not explored further. However, another student persisted, 'Racist people tease people because of the colour of their skin'. Blake replied by confirming what the student said, 'So people may be racist to them because they are Indigenous?' as a way to prompt further discussion. As the discussion continued, a few students continued to raise the original topic of mistreatment. One student talked about a family member who experienced apartheid in South Africa and described race-based segregation. Lisa briefly explained what segregation was but again, did not discuss reasons why this happened.

Compared to HFPS and LPS, teachers at MPS talked more openly about skin colour and racism. As a result, more nuanced distinctions were drawn between talking about race (racialisation) and racism. The teacher, Rebecca, then supported students to think about what is and isn't racist. Similar to adult conceptualisations of racism (Walton, Priest and Paradies 2013a), students drew on contextual clues such as familiarity, intent and effect of speech to determine whether something was racist. In the following discussion, they talked about whether using 'nigger', a highly racist derogatory word, was always racist depending on the intent (e.g. a 'joking' context), who was saying it and to whom and whether it could potentially offend someone else that overheard. Student 2 was the only Anglo-Celtic student in the classroom. One student asked, 'If you're joking around with a friend is it still racist?' Other students around the room said, 'No.': 
Student 2: $\quad$ Some people say it as a joke.

Rebecca: Is that racism? If [a student] came up to me and said, 'What's up nigger?'

Student 3: If a friend says it, it's a greeting. You have to use the greeting to someone you know really well.

Rebecca: So you have to have a relationship? You have to have a relationship with someone and it's about their intent. How do you know what their intent is? Voice, facial expression?

Student 4: And the voice that you use. If someone was white and said to you ...

Rebecca: What if [Student 2] said it?

Student 2: $\quad$ It would be racist if I said it but not if he said it to him. If you talk to your own skin colour [it's okay] [...]

Rebecca: It's okay if someone is your friend? If you have a positive social relationship with someone, there are different boundaries.

Student 2: $\quad$ If you said something to a friend, what if someone else heard it? They might take it differently. (MPS Grade 5\&6 Classroom observations, 15/11/11)

Later on, the topic was brought up again with one student asking, 'Is it racist to laugh at a racist joke?' to which another student replied, 'Yes it is.' They concluded that if someone tells a joke and it is considered to be racist (not just racialised) after assessing the context in which it was said, then it is racist to laugh by supporting the joke. These students demonstrated sophisticated theorising about identifying race-based talk as racist based on a number of contextual factors.

Rebecca: Is it racist to tease someone's accent?

Student 5: $\quad$ It is racist because that's how you are, you can't change that unless you go to another country early on.

Student 6: The others thought accent was racist, but I don't. It depends, some people mimic accents they might not.

Rebecca: If you don't intend it, is it racist?

Student 1: $\quad$ It depends on the way the person takes it.

Rebecca: If we're trying to build relationships with diverse people, we need to know what racism is. (MPS Classroom observations, Grade 5\&6, 15/11/11)

It is likely such sophisticated discussions would be possible at CPS, where there was also a racially and ethnically diverse student population, if the teachers were skilled and confident in facilitating such conversations.

\section{Parent approaches}

Parent approaches to discussing racism and cultural diversity ranged from silence and de-emphasising difference to recognising and engaging in critical conversations about racism. Overwhelmingly though, parents reported 
taking a similar approach to the majority of teachers in this study by talking about racism only when their children raised it or, more commonly, dismissing it as wrong without explaining why. Most parents, like many teachers, felt it was acceptable to talk about culture rather than race or ethnicity. However, some parents at HFPS indicated that even highlighting difference was considered unnecessary:

I'd definitely say I'm in the camp where we don't initiate conversations and I think that's more along the lines of I wouldn't want to bring to their attention that someone was different or that something needed discussing. It's more that it just is. Unless they ask a question about it we just accept that that's how it is so I wouldn't be initiating, 'Why do you think they're doing that?' or 'Why do you think we do it this way and they do it that way?' because I think that where I'm coming from is that, that's drawing attention to the differences. (HFPS Parent FG, 14/11/11)

Another parent suggested that thinking about individual differences is something that adults consider meaningful whereas for children she felt it was the opposite: 'They don't care. I don't think the kids care. I don't think they notice' (HFPS Parent FG, 14/11/11).

For these parents, talking about difference is construed as not only irrelevant or inconsequential, but also as something that draws unnecessary attention to perceived barriers between people. Therefore, focusing on how everyone is the same was considered favourable to thinking about how people are different. As one parent put it, 'Different is just different. Different is not good. Different is not bad' (HFPS Parent FG, 14/11/11). In the process, the positive and negative ways that difference is meaningful in society is rendered irrelevant and thereby reinforced. Drawing on Pollock's (2004) concept of 'colourmute', which refers to the active silencing of any form of race-talk, such a strident belief in a post-racial society contributes to mute inaction in which any mention of difference is deemed superfluous and any type of 'race-talk' is labelled racist. A few Anglo-Celtic parents in the CPS focus group noted that everyone should be treated 'as one'. The practical result of this is that everyone is expected to conform to the same societal and school norms (i.e., as determined by the majority group). For example, they felt that all students should be expected to only speak English at school. Their sentiments echoed those of some of the Anglo-Celtic students at HFPS who talked about a few students speaking Chinese and feeling left out because they do not understand or assuming that they are saying something negative about them (HFPS Student FG\#2, 17/11/11). The parents' discourse also revealed underlying anxieties about their position of privilege in moments when they became momentarily 'other'. 
Brenda: It's good to know we're all one here, we should be all treated as one here.

Michelle: While they're here then I feel they should speak our language and not speak their language during school time.

Brenda: And if they are speaking their language here well exactly, they could be calling you you-know-what and you don't know what so it's like they do have something to hide.

(CPS Parent FG, 24/11/11)

Therefore, under the premise that everyone is the same, any act that draws attention to difference, such as speaking another language, is not only unacceptable but can be used as evidence of the 'other' not fitting in (Hage 2008).

In spite of a strong push toward colour-blindness and being 'colourmute', other parents understood that talking about racism is difficult but necessary. They thought it was important for their children to have the tools to know when and how to challenge something they find unacceptable.

Claire: $\quad$ But challenging behaviour with a kid, and showing a kid that you challenge that behaviour is a really important thing to do as well. Because as they go forward in their lives, the biggest thing you can give them is that the ability to stand up for what is not acceptable.

Mary: And what they believe in.

Claire: $\quad$ Yep.

Abby: $\quad$ Even if it is tough.

Claire: Even if it is a difficult conversation. (LPS Parent FG, 29/03/12)

The importance of knowing how to act appropriately was reiterated by students who said that their parents would use strategies, such as modelling respectful behaviour, explaining why it was important not to be racist and being open-minded and respectful.

Finally, similar to teachers and students, parents were also unsure about whether talking about race was always racist. An Aboriginal parent explained that her child had questions about whether using the words 'black' and 'white' meant that it was racist.

At the moment she's got a very black and white view about racism. So just trying to get her to think a bit more about what racism is and her understanding of racism because I know we might be talking about, might be something like even with the word black in it and she'll go, 'But that's racist' and I'll have to explain what racism is. That it's not actually when you're talking about a black cat. (CPS Parent Interview, 16/12/11)

Compared to teachers and parents who did not feel comfortable or confident talking about race, this parent helped her child understand how race is made 
meaningful and that words alone, such as 'black' and 'white' do not necessarily signify race or indicate racism.

Parents at LPS also discussed how they might identify something as racist. Similar to the students, they also considered relationships, familiarity, intent and effect of speech (Walton et al. 2013a). Even though none of the parents were explicitly asked to think about how they might identify racism, questions about how they would talk to their child about various cultural and racial/ethnic scenarios sometimes resulted in complex theorising about racism. The parents talked about their personal experiences of race-based talk:

Maggie: $\quad$ Yeah well it is tone and ...

Iris: Well yeah, like on the sporting field and we have a lot of friends who call themselves 'wogs' [...]

Mary: $\quad$ My husband calls me a Lebo.

Maggie: $\quad$ It does not make you angry, does it?

Mary: $\quad$ Not at all. No, no, no.

Abby: But you would not say that to a stranger. (LPS Parent FG, 29/3/12)

These parents talked about the social context of demeaning words such as 'wog' and 'Lebo' referring to people of Mediterranean and Lebanese backgrounds, respectively. They explained that while it was sometimes acceptable to use those words if the target person is not offended, it was not acceptable to use it with everyone.

\section{Conclusion}

This study not only confirms research evidence that children notice race and begin to develop particular attitudes toward people from different racial, ethnic and cultural backgrounds from a young age, it also demonstrates that children seek to understand the social meaning of race and racism in terms of their everyday experiences. Interestingly, teachers (e.g. MPS) who created an authorising classroom environment that encouraged children to openly discuss issues and experiences of racism resulted in children also engaging in complex theorising about differences between racism and racialisation. For example, students at MPS confused racism with racialisation, assuming that any mention of race or skin colour was racist. Other students debated whether racism can be based on other aspects besides skin colour such as culture and religion. The students' discussions highlighted what Martin Barker (1981) called, 'new racism' or racism based on cultural attributes rather than visible physical traits, which nevertheless has the same effect to rank groups of people in a hierarchical order (Eriksen 2010). 
Additionally, these findings demonstrate that while children could identify blatant forms of racism (as overt, aggressive, exclusionary and judgmental), more subtle forms are likely to remain undetected and unaddressed. This is similar to the ways Australian adults in another study identified racism (Walton et al. 2013a), which saw more subtle forms such as race-based jokes as more ambiguous and more socially acceptable. Not being able to identify more banal forms of everyday racism (Essed 1991) also obscures the ways privilege operates to reinforce inequities at an interpersonal level through behaviours such as stereotypes and subtle exclusion to those at a systemic level in terms of housing and employment. These findings demonstrate that children also need the tools to understand how to identify more subtle forms of racism. By not engaging in in-depth discussion about these topics, as with the teachers at HFPS, students are left with an uncritical understanding of race and its meaning in society.

In focus groups and classroom observations, students at LPS, HFPS and CPS also described an awareness of race and racism. However, during classroom observations, discussions were limited despite highly relevant curriculum content, which included the White Australia Policy and the Stolen Generations. Key differences for these schools included teacher professional capabilities and confidence to engage in critical discussions, perceived need based on student racial, ethnic and cultural demographics and support from school leadership and parents. While some teachers and parents understood that children need to engage in age-appropriate discussions about the meaning of race and racism, many teachers also explained that they did not always feel confident or supported (by school leaders and parents) to do so. As a result, classroom discussions tended to focus mainly on learning about cultural diversity with occasional talk about skin colour and inequality. It is also possible that compared to MPS, issues of race and racism were not as immediately pertinent to the everyday lives of students at HFPS and LPS as they were mainly from white Australian backgrounds and as the majority culture, less likely to experience racism.

However, despite some teachers at HFPS insisting that their students did not notice skin colour, a number of students exhibited racist attitudes toward students with Chinese backgrounds. Teachers at this school took a 'racelessness' pedagogical stance, which supports the idea that it is more appropriate and socially progressive to not draw attention to racial or ethnic factors in social situations. This stance is aligned with a colour-blind approach, which claims to not notice racial differences. Compared to students at MPS, these students were not actively supported to discuss difficult issues about racism and prejudiced attitudes toward racial, ethnic and cultural diversity. As a result, racist behaviours and attitudes may have gone unnoticed or left unchallenged. Importantly, emerging research evidence suggests that supporting a critical understanding of racism in the context of promoting positive attitudes about racial, ethnic and cultural diversity can benefit students 
including developing a more open and varied understanding of people from diverse backgrounds (Lee, Gamsey and Sweeney 2008; Walton et al. 2013b).

\section{Recommendations}

Overall, while most teachers and parents recognised the need for students to learn about their own culture and other cultures, with a few recognising the importance of having a critical understanding of racism, they often did not feel confident engaging in such conversations. To varying degrees, teachers, parents and students discussed what constitutes racism, how to identify race-talk as racist and how to talk about racism. Some teachers such as those at LPS recognised that it was important to dispel stereotypes and to promote positive attitudes toward people from diverse backgrounds. However, there was clearly need for professional support and more explicit educational guidelines on how to talk about racism and cultural diversity in critical and appropriate ways with their students and children. While critical multiculturalism clearly identifies the need to move beyond celebratory approaches to talking about racial-ethnic diversity and cultural difference (Banks and Banks 2007; May and Sleeter 2010; Sleeter and Grant 2009; Zirkel 2008), this study highlights that we need to know more about how we can support teachers and parents to do this within their everyday lives and settings. More research is also required on how children from both majority and minority racial-ethnic backgrounds negotiate race, racialisation and racism across different contexts, and how best to support them to do so in positive ways within their particular settings (Pedersen et al. 2011). A few parents from LPS were particularly comfortable in talking about these topics with their children but understood that not all parents have that knowledge or confidence.

Teachers primarily discussed professional development and support from school leadership and parents as key factors for including lessons about cultural diversity and racism in the curriculum. Based on the current findings, professional development programs need to particularly target schools with a majority white student population as these students, teachers and parents tended to discuss issues relating to race and racism much less than teachers and students from schools with higher ethnic-racial diversity. This is an important recommendation as research shows that there are clear benefits of learning about race and racism for students from both majority and minority backgrounds (Walton et al. 2013b).

Teachers obviously cannot bear the full responsibility of addressing racism and teaching children to recognise and stand against it. Based on the similar parent and teacher findings from this study, all significant adults who play a role in socialising children about ethnic and racial diversity, first of all, need to be supported to reflect on their own positionality in society 
and how racism and privilege intersect to reinforce social inequities (Howard and Flennaugh 2011; Hylton 2012; Kempf 2013; Smith and Lalonde 2003). Importantly, a multilevel approach is needed so that these messages are reinforced at an interpersonal level amongst friends and family, within schools, workplaces and the broader community as well as at a systemic level to set the standards in terms of policy and practice. Importantly, parents and teachers need to understand that despite idealistic values for a post-racial society, beliefs that children are innocent and oblivious to social problems, children also live within the same world as adults and are increasingly exposed to these issues of race, racialisation and racism through technology such as the Internet. Without appropriate support and open discussion from an early age, there is the risk of unchallenged prejudiced attitudes being reinforced in childhood and into adulthood. Finally, our findings show that, although discussing both racial sameness and difference is challenging for teachers and parents, a more active stance is necessary so that children can be prepared for a world where race and racism have enduring social significance.

\section{Funding}

Dr Priest was supported by an NHMRC Postdoctoral Research Fellowship [628897]; and by the Victorian Health Promotion Foundation. This project was funded by a Victorian Health Promotion Foundation Innovation Grant.

\section{Notes}

1. The term 'wog' has historically been used in Australia to demean people from a Mediterranean background (e.g. Italians and Greeks). In recent times, it has been reappropriated by people from these backgrounds as a term of empowerment and shared identity (Sala, Dandy and Rapley 2010).

2. 'Ocker' refers to those with an exaggerated broad Australian accent who use Australian slang, often either affectionately or derogatorily associated with people from a working-class background.

3. This refers to official Australian government policies from 1909 to 1969, which systematically allowed Aboriginal and Torres Strait Islander children of 'mixed' descent to be forcibly removed from their families without parental consent.

\section{References}

Aboud, F. E., C. Tredoux, L. R. Tropp, C. S. Brown, U. Niens, N. M. Noor, and U. G. E. Group. 2012. "Interventions to Reduce Prejudice and Enhance Inclusion and Respect for Ethnic Differences in Early Childhood: A Systematic Review." Developmental Review 32 (4): 307-336.

Alderson, P. 2001. "Research by Children." International Journal of Social Research Methodology 4: 139-154. 
Apfelbaum, E. P., M. I. Norton, and S. R. Sommers. 2012. "Racial Color Blindness: Emergence, Practice and Implications." Current Directions in Psychological Science 21 (3): 205-209.

Apfelbaum, E. P., K. Pauker, S. R. Sommers, and N. Ambady. 2010. "In Blind Pursuit of Racial Equality?" Psychological Science 21: 1587-1592.

Atree, P. 2007. "The Social Costs of Child Poverty: A Systematic Review of the Qualitative Evidence." Children and Society 20: 54-66.

Baker, J., and S. Weller. 2003. "'Is it Fun?' Developing Children Centered Research Methods." Journal of Sociology and Social Policy 23: 33-58.

Banks, J. A., and C. A. M. Banks, eds. 2007. Multicultural Education: Issues and Perspectives. 6th ed. Hoboken, NJ: Wiley.

Barker, M. 1981. The New Racism: Conservatives and the Ideology of the Tribe. London: Junction Books.

Berman, G., and Y. Paradies. 2010. "Racism, Disadvantage and Multiculturalism: Towards Effective Anti-racist Praxis." Ethnic and Racial Studies 33 (2): 214-232.

Boutte, G., J. Lopez-Robertson, and E. Powers-Costello. 2011. "Moving beyond Colorblindness in Early Childhood Classrooms." Early Childhood Education Journal 39 (5): 335-342.

Brown, C. S., and R. S. Bigler. 2005. “Children's Perceptions of Discrimination: A Developmental Model." Child Development 76 (3): 533-553.

Castagno, A. E. 2008. “'I Don't Want to Hear That!': Legitimating Whiteness through Silence in Schools." Anthropology \& Education Quarterly 39 (3): 314-333.

Clavering, E. K., and J. McLaughlin. 2010. "Children's Participation in Health Research: From Objects to Agents?" Child: Care, Health and Development 36 (5): 603-611.

Cohen, L., L. Manion, and K. Morrison. 2007. Research Methods in Education. 6th ed. London: Routledge.

Darbyshire, P., C. MacDougall, and W. Schiller. 2005. "Multiple Methods in Qualitative Research with Children: More Insight or Just More?" Qualitative Research 5 (4): 417-436.

Delgado, R., and J. Stefancic. 2001. Critical Race Theory: An Introduction. New York: NYU Press.

Denzin, N. K., and Y. S. Lincoln, eds. 2011. The SAGE Handbook of Qualitative Research. 2nd ed. Thousand Oaks, CA: Sage.

Eriksen, T. H. 2010. Ethnicity and Nationalism: Anthropological Perspectives. 3rd ed. London: Pluto Press.

Essed, P. 1991. Understanding Everyday Racism: An Interdisciplinary Theory. Newbury Park, CA: Sage.

Giroux, S. 2006. "On the State of Race Theory: A Conversation with David Theo Goldberg." JAC: A Journal of Rhetoric, Culture \& Politics 26 (1-2): 11-66.

Hage, G. 2008. "Analysing Multiculturalism Today." In The SAGE Handbook of Cultural Analysis, edited by T. Bennett and J. Frow, 488-509. London: SAGE.

Hall, S. 2000. "Old and New Identities, Old and New Ethnicities." In Theories of Race \& Racism, edited by L. Back and J. Solomos, 144-153. New York: Routledge.

Hartmann, D., D. Winchester, P. Edgell, and J. Gerteis. 2011. "How Americans Understand Racial and Religious Differences: A Test of Parallel Items from a National Survey." Sociological Quarterly 52 (3): 323-345.

Howard, T. C., and T. K. Flennaugh. 2011. "Research Cautions, Concerns and Considerations on Black Males in a 'Post Racial' Society." Race, Ethnicity, \& Education 14 (1): 105-120. 
Hylton, K. 2012. "Talk the Talk, Walk the Walk: Defining Critical Race Theory in Research." Race Ethnicity and Education 15 (1): 23-41.

Jaasma, M. A. 2001. "Sixth Graders Speak Out: Troublesome Intercultural Encounters." Paper presented at the Annual Convention of the Western States Communication Association, Coeur d'Alene, Idaho, February 23-27.

Kempf, A. 2012. "Colour-blind Praxis in Havana: Interrogating Cuban Teacher Discourses of Race and Racelessness." Race, Ethnicity and Education 16 (2): 246-267.

Kempf, A. 2013. "Post-racialism in the Classroom as Anti-racist Practice in Cuba." Latin American and Caribbean Ethnic Studies 9 (1): 44-64.

Lee, R., P. G. Gamsey, and B. Sweeney. 2008. "Engaging Young Children in Activities and Conversations about Race and Social Class." Young Children 63 (6): 68-76.

MacDougall, C., and F. Baum. 1997. "The Devil's Advocate: A Strategy to Avoid Groupthink and Stimulate Discussion in Focus Groups." Qualitative Health Research 7 (4): 532-541.

MacDougall, C., and E. Fudge. 2001. "Planning and Recruiting the Sample for Focus Groups and In-depth Interviews." Qualitative Health Research: An International Interdisciplinary Journal 11 (1): 117-126.

May, S., and C. E. Sleeter, eds. 2010. Critical Multiculturalism: Theory and Praxis. New York: Routledge.

Moon, S., J. Jung, Y. S. Bang, K. Yum Kwon, and Y. Suh. 2009. “'I Don't See Color; I Only See Children!': A Study of Teachers' Color-blindness for Asian Students/Family." US-China Education Review 6 (8): 80-84.

Moran, A. 2011. "Multiculturalism as Nation-building in Australia: Inclusive National Identity and the Embrace of Diversity." Ethnic and Racial Studies 34 (12): 2153-2172.

Morgan, M., S. Gibbs, K. Maxwell, and N. Britten. 2002. "Hearing Children's Voices: Methodological Issues in Conducting Focus Groups with Children Aged 7-11 Years." Qualitative Research 2: 5-20.

Morrow, V. 2001. "Using Qualitative Methods to Elicit Young People's Perspectives on Their Environments: Some Ideas for Community Health Initiatives." Health Education Research 16 (3): 255-268.

Morse, J. M., and L. Richards. 2002. Read Me First for a User's Guide to Qualitative Methods. Thousand Oaks, CA: SAGE.

Ono, K. A. 2010. "Postracism: A Theory of the 'Post-' as Political Strategy." Journal of Communication Inquiry 34: 227-233.

Paluck, E. L., and D. P. Green. 2009. "Prejudice Reduction: What Works? A Review and Assessment of Research and Practice." Annual Review of Psychology 60: 339-367.

Pedersen, A., I. Walker, Y. Paradies, and B. Guerin. 2011. "How to Cook Rice: A Review of Ingredients for Teaching Anti-prejudice.” Australian Psychologist 46 (1): 55-63.

Pica-Smith, C. 2009. "Children Speak about Interethnic and Interracial Friendships in the Classroom: Lessons for Teachers." Multicultural Education 17: 38-47.

Pollock, M. 2004. Colormute: Race Talk Dilemmas in an American High School. Princeton, NJ: Princeton University Press.

Priest, N., J. Walton, F. White, E. Kowal, A. Baker, and Y. Paradies. 2014. "Understanding the Complexities of Ethnic-racial Socialization Processes for Both Minority and Majority Groups: A 30-Year Review." International Journal of Intercultural Relations. doi: 10.1016/j.ijintrel.2014.08.003. 
Punch, S. 2002. "Research with Children: The Same or Different from Research with Adults?" Childhood 9: 321-341.

Raabe, T., and A. Beelmann. 2011. "Development of Ethnic, Racial, and National Prejudice in Childhood and Adolescence: A Multinational Meta-analysis of Age Difference." Child Development 82 (6): 1715-1737.

Rice, P. L., and D. Ezzy. 1999. Qualitative Research Methods: A Health Focus. Oxford: Oxford University Press.

Sala, E., J. Dandy, and M. Rapley. 2010. "Real Italians and Wogs': The Discursive Construction of Italian Identity among First Generation Italian Immigrants in Western Australia." Journal of Community and Applied Social Psychology 20 (2): $110-124$.

Sleeter, C. E., and C. A. Grant. 2009. Making Choices for Multicultural Education: Five Approaches to Race, Class, and Gender. 6th ed. Hoboken, NJ: John Wiley \& Sons.

Smith, E. P., J. Atkins, and C. M. Connell. 2003. "Family, School, and Community Factors and Relationships to Racial-ethnic Attitudes and Academic Achievement." American Journal of Community Psychology 32 (1/2): 159-173.

Smith, A., and R. N. Lalonde. 2003. "Racelessness' in a Canadian Context? Exploring the Link between Black Students' Identity, Achievement and Mental Health." Journal of Black Psychology 29: 142-164.

Supphellen, M., O. A. Kvitastein, and S. T. Johanson. 1997. "Projective Questioning and Ethnic Discrimination: A Procedure for Measuring Employer Bias." Public Opinion Quarterly 61: 208-224.

Una Qualitative Methods Learning Group. 2010. Researching 'Race' and Ethnicity with Children: Qualitative Research Approaches, Methods, Techniques and Findings. Belfast: Una.

Walton, J., N. Priest, E. Kowal, K. Brickwood, B. Fox, F. White, and Y. Paradies. 2014. "Talking Culture? Egalitarianism, Color-blindness and Racism in Australian Elementary Schools." Teaching \& Teacher Education 39: 112-122.

Walton, J., N. Priest, and Y. Paradies. 2013a. "Identifying and Developing Effective Approaches to Foster Intercultural Understanding in Schools." Intercultural Education 24 (3): 181-194.

Walton, J., N. Priest, and Y. Paradies. 2013b. "“It Depends How You're Saying It': The Conceptual Complexities of Everyday Racism." International Journal of Conflict and Violence 7 (1): 74-90.

Washington, R. E. 1990. "Brown Racism and the Formation of a World System of Racial Stratification." International Journal of Politics, Culture, and Society 4 (2): 209-227.

Willis, K., J. Green, J. Daly, L. Williamson, and M. Bandyopadhyay. 2009. "Perils and Possibilities: Achieving Best Evidence from Focus Groups in Public Health Research." Australian and New Zealand Journal of Public Health 33 (2): 131-136.

Yin, R. K. 2004. Applications of Case Study Research. Thousand Oaks, CA: Sage.

Yin, R. K. 2009. Case Study Research: Design and Methods. Thousand Oaks, CA: Sage.

Zembylas, M. 2010. "Children's Construction and Experience of Racism and Nationalism in Greek-cypriot Primary Schools." Childhood 17 (3): 312-328.

Zirkel, S. 2008. "The Influence of Multicultural Educational Practices on Student Outcomes and Intergroup Relations." Teachers College Record 110: 1147-1181. 